\title{
Modeling meets science and technology: an introduction to a special issue on negative emissions
}

\author{
Massimo Tavoni • Robert Socolow
}

Received: 20 December 2012 / Accepted: 26 March 2013 / Published online: 17 April 2013

(C) The Author(s) 2013. This article is published with open access at Springerlink.com

\begin{abstract}
This article introduces the Climatic Change special issue dedicated to negative emissions technologies, also known as carbon dioxide removal (CDR) from the atmosphere. $\mathrm{CDR}$ is the only class of mitigation options able to reduce the carbon stock in the atmosphere significantly. In this special issue CDR is explored from the perspectives of integrated assessment, technology optimization, environmental science, and political science.
\end{abstract}

\section{Why this special issue?}

This special issue has a theme and a message. The theme is deliberate carbon dioxide removal (CDR) from the atmosphere; all nine papers that follow this introductory essay deal with CDR. The message is that complementary exploration of a single subject through integrated assessment modeling (IAM) and through other disciplinary investigations can result in a beneficial iterative process. Five of the papers use IAM to investigate CDR. The other four papers approach CDR through the lenses of ecology, carbon-cycle science, chemical engineering, and political science.

This article is part of a Special Issue on "Carbon Dioxide Removal from the Atmosphere: Complementary Insights from Science and Modeling” edited by Massimo Tavoni and Robert Socolow.

Producing this special issue has involved constructive interaction with the authors of the nine papers. We are especially grateful for the willingness of the lead authors (Chen Chen, Jae Edmonds, Sabine Fuss, Elmar Kriegler, Marco Mazzotti, James Meadowcroft, Lydia Smith, Marcello Vichi, and Detlef van Vuuren) and their coauthors to address our persistent inquiries and to provide us with the data in the Tables. We would also like to thanks the editors of Climatic Change, Michael Oppenheimer and Gary Yohe, for their encouragement and advice. Finally, we would like to thank Kristin Kuntz-Duriseti for her invaluable support during the lengthy editorial process. This work is part of the research developed under the GEMINA project, funded by the Italian Ministries for the Research and for the Environment, Land and Sea.

M. Tavoni $(\bowtie)$

Euro-Mediterranean Center on Climate Change (CMCC) and Fondazione Eni Enrico Mattei (FEEM), Milano, Italy

e-mail: mtavoni@princeton.edu

R. Socolow

Princeton University, Princeton, NJ, USA

e-mail: socolow@princeton.edu 
Our intention is to increase communication between those who explore CDR-related science and technology and those who introduce CDR into models. Through these articles modelers will learn about the incompleteness of current understanding of the CDR option, and those involved in characterizing CDR science and technology will appreciate the questions modelers need help answering. Encouraged by Carlo Carraro, coordinator of climate change research at Fondazione Eni Enrico Mattei (FEEM) and Euro-Mediterranean Center on Climate Change (CMCC), we organized a meeting in Venice in May, 2011, to bring these perspectives together. In this special issue of Climatic Change most of the papers from that workshop have become articles.

CDR is important because it empowers "overshoot" trajectories (den Elzen and van Vuuren 2007). An overshoot trajectory achieves a $\mathrm{CO}_{2 \mathrm{e}}$ concentration target at a specific future time while exceeding that target during some intermediate time. Due to $\mathrm{CO}_{2}$ absorption by the natural land and ocean sinks, overshoot is possible even without CDR. The engineered sinks probed in these models supplement these natural sinks. Indeed, when CDR technologies are cost-competitive and the atmospheric $\mathrm{CO}_{2 \mathrm{e}}$ concentration is tightly constrained at some distant date (usually 2100), an overshoot trajectory often emerges. To be sure, the overshoot period could bring irreversible damage that would not have occurred if the target for 2100 had never been exceeded.

Overshoot trajectories and associated CDR strategies are closely linked to the feasibility of long-term climate stabilization policies. In the Fourth Assessment Report (AR4) of the IPCC most of the scenarios focused on targets where 550-650 $\mathrm{CO}_{2 \mathrm{e}}$ never to be exceeded, and only a few scenarios focused on more stringent targets. With AR5, policymakers asked modelers to focus on stringent objectives like the "two degrees" target, where the planet's average surface temperature never exceeds its preindustrial value (200 years ago) by more than $2{ }^{\circ} \mathrm{C}$. The AR4 scenarios with stringent targets featured CDR and were new to the modeling community, which became concerned that AR4 would be read as biased favorably toward the feasibility of the $2{ }^{\circ} \mathrm{C}$ target (Tavoni and Tol 2010). Subsequently, many models have incorporated CDR, thereby increasing the options for achieving stringent climate targets. Thus, paradoxically, despite little progress in international climate policy and increasing emissions, long-term climate stabilization through the lens of IAM appears easier and less expensive. CDR allows the mitigation burden to shift away from early periods. Clearly, it matters whether substantial overshooting via CDR is a credible proposition.

A CDR strategy necessarily requires moving atmospheric carbon elsewhere. In the articles in this volume, "elsewhere" is either the biosphere (whose carbon stock thereby increases) or porous geological formations deep below ground. The method of removal of atmospheric carbon is either photosynthesis or air flow across inorganic chemical sorbents. Three of the four resulting options are explored in this issue:

1) Biological capture and biological storage (afforestation, soil-carbon build-up).

2) Biological capture and geological storage - an option known BECCS (Biological Energy production with associated geological Carbon dioxide Capture and Storage). In BECCS, an energy crop is produced, harvested, and converted into either electricity or fuel; much of the $\mathrm{CO}_{2}$ generated at the energy conversion site is captured and stored. A carbon atom removed from the atmosphere by photosynthesis is sent below ground, and the atmosphere is scrubbed of some of its $\mathrm{CO}_{2}$.

3) Non-biological capture and geological storage - an option known as DAC (Direct Air Capture of Carbon dioxide with chemicals). In DAC, air flows over a chemical sorbent which preferentially removes $\mathrm{CO}_{2}$, and the resulting concentrated $\mathrm{CO}_{2}$ is injected deep underground. 
An example of the fourth option, non-biological capture and biological storage, would concentrate $\mathrm{CO}_{2}$ with chemicals and use the concentrated gas mixture to stimulate the growth of long-lived plants.

The remainder of this introductory article is divided into four sections. Section 2 provides a view across the five modelling papers and discusses common themes. Section 3 extracts from the three science and technology papers insights relevant to the current state of the art of integrated assessment. Section 4 builds on our political science article to suggest avenues for further research. Section 5 is a brief summary.

\section{A view across the five modeling papers}

Five papers in this special issue explore CDR using economic models. The subsections here address the models, their targets, and their CDR strategies; biological and geological constraints; and the resulting levels of deployment.

\subsection{Models, targets, and strategies}

In this special issue five models assess the role and potential of CDR in the context of long-term climate stabilization (see Table 1). Four are well established state-of-the-art IAMs: GCAM (Edmonds et al. 2013), IMAGE (Van Vuuren et al. 2013), REMIND (Kriegler et al. 2013) and WITCH (Chen and Tavoni 2013). The fifth (Fuss et al. 2013) is an original, stylized model tailored to answer specific questions about the interaction of CDR deployment with uncertainties in the magnitude of the climate change threat.

The four IAMs are century-scale models that either simulate (GCAM and IMAGE) or optimize (REMIND and WITCH) a cost-effective strategy to reduce greenhouse gas emissions. In the simulation models equilibria are developed for each point in time, while for the optimization models the whole temporal dynamics is resolved at once, assuming a forwardlooking planner with perfect foresight who discounts future wellbeing.

In all cases the target is a concentration of $\mathrm{CO}_{2 \mathrm{e}}$ not to be exceeded in 2100 . The target concentration is not exactly equal across papers, but it is stringent and roughly in line with an increase of the average surface temperature capped at $2.0^{\circ} \mathrm{C}$ to $2.5^{\circ} \mathrm{C}$. Importantly, the concentration objective can be exceeded at intermediate times, because subsequently CDR can reduce the $\mathrm{CO}_{2}$ concentration.

Climate feedbacks on these trajectories are not included in the models. Thus, incremental damage during overshoot periods is not taken into account. Damage-trajectory relationships are complex, because damage is associated with both short-term forcing (which impacts meteorology) and integrated forcing (which affects large-time-constant behavior such as icesheet melting and ocean warming). With a slightly lower concentration in 2100 than in 2070 , for example, should one expect to see any reduction by 2100 of the storm severity and ice melting seen in 2070 ?

The technological resolution of CDR varies across the models. Edmonds et al. and Van Vuuren et al. model "yield" (biomass production per hectare per year) and land area. Only Edmonds et al. develops the biomass energy supply from a model (GCAM) that fully couples the economy, energy, and land use. The other models rely on a soft coupling to the land and introduce cost curves for bioenergy supply exogenously.

As summarized in Table 1, four CDR strategies are explored by at least one model. All models give prominence to biological energy production with $\mathrm{CO}_{2}$ capture and storage (BECCS). Edmonds et al. also includes afforestation and storage of carbon in materials (such 
Table 1 The role of $\mathrm{CO}_{2}$ removal in climate stabilization policy in this issue's five integrated assessment models. Data were obtained by polling the authors, and some data are not found in their articles

\begin{tabular}{|c|c|c|c|c|c|}
\hline Paper & Model & $\begin{array}{l}\text { CDR options explored } \\
\text { in addition to } \\
\text { BECCS }^{\mathrm{a}}\end{array}$ & $\begin{array}{l}\text { Cumulative CDR } \\
\text { to } 2100\left(\mathrm{GtCO}_{2}\right)\end{array}$ & $\begin{array}{l}\mathrm{CDR} \text { maximum } \\
\text { rate }\left(\mathrm{GtCO}_{2} / \mathrm{yr}\right)\end{array}$ & $\begin{array}{l}\text { Climate overshoot: } \\
\text { concentration and } \\
\text { temperature }\end{array}$ \\
\hline $\begin{array}{l}\text { Edmonds } \\
\text { et al. }\end{array}$ & GCAM & $\begin{array}{l}\text { Afforestation, storage } \\
\text { in materials } \\
\text { (e.g., plastics) }\end{array}$ & $\begin{array}{l}\text { Terrestrial: 200-700; } \\
\text { BECCS (net): } \\
\text { 460-680 }\end{array}$ & 20 & $\begin{array}{l}55-135 \text { ppm-eq } \\
0.2-0.5{ }^{\circ} \mathrm{C}\end{array}$ \\
\hline $\begin{array}{l}\text { Van Vuuren } \\
\text { et al. }\end{array}$ & IMAGE & None & 800 & $10-15$ & n.a. ${ }^{b}$ \\
\hline $\begin{array}{l}\text { Kriegler } \\
\text { et al. }\end{array}$ & REMIND & None & $470-910$ & $11-14$ & $\begin{array}{l}40 \text { ppm-eq } \\
0.05^{\circ} \mathrm{C}\end{array}$ \\
\hline $\begin{array}{l}\text { Chen and } \\
\text { Tavoni }\end{array}$ & WITCH & $\mathrm{DAC}^{\mathrm{c}}$ & $\begin{array}{l}\text { DAC: } 477 ; \\
\text { BECCS: } 300\end{array}$ & 35 & $\begin{array}{l}60 \text { ppm-eq } \\
0.06{ }^{\circ} \mathrm{C}\end{array}$ \\
\hline Fuss et al. & $\begin{array}{r}\text { Stylized } \\
\text { model }\end{array}$ & DAC & $1600^{\mathrm{d}}$ & 32 & n.a. \\
\hline
\end{tabular}

\footnotetext{
${ }^{\text {a }}$ Fuss et al. deals with a generic BECCS. BECCS is explored for electricity only in Chen \& Tavoni; for electricity and fuels in Edmonds et al. and Van Vuuren et al.; and for electricity, fuels, and hydrogen in Kriegler et al.

${ }^{\mathrm{b}}$ Not available

${ }^{\mathrm{c}} \mathrm{DAC}$ direct capture of $\mathrm{CO}_{2}$ from air with chemicals and $\mathrm{CO}_{2}$ storage

${ }^{\mathrm{d}}$ Base case scenarios
}

as plastics). Both Chen \& Tavoni and Fuss et al. include Direct Air Capture of $\mathrm{CO}_{2}$ with chemicals (DAC). These four strategies illuminate many of the key issues raised by CDR, notably co-benefits, gross vs. net emissions, and demands on land. Among the CDR strategies that are not explored at all are ocean-based strategies such as iron fertilization and land-based strategies such as biochar.

From the perspective of integrated assessment modeling, the CDR options are just another set of technologies for mitigating climate change, competing with the usual list of strategies, such as efficiency, renewables, CCS, and nuclear power. Cost trajectories and quantity constraints for the CDR strategies are the key new information introduced into the models. This competition is particularly transparent in Fuss et al., where the assumed cost of removing a marginal percent of baseline $\mathrm{CO}_{2}$ emissions is constant over time but depends exponentially on the percent already removed: the marginal costs of abating $25 \%, 50 \%$, and $75 \%$ of baseline emissions are, respectively, about $\$ 10 / \mathrm{tCO}_{2}, \$ 100 / \mathrm{tCO}_{2}$, and $\$ 1000 / \mathrm{tCO}_{2}$.

The four IAMs disaggregate the world into macro-regions (roughly 12-14 macro regions for all models except IMAGE, which has twice as many) which interact through trading. Edmonds et al. and Chen \& Tavoni explore both differential regional compliance with global agreements and differential regional endowments affecting CDR capability (such as geological storage capacity). In Edmonds et al. and Chen \& Tavoni, delayed participation can result in regional emissions that exceed some pre-specified cumulative global emissions, making the corresponding $\mathrm{CO}_{2 \mathrm{e}}$ concentration target unobtainable. As a consequence of differential endowments, Chen \& Tavoni expects BECCS to be implemented primarily in Latin America and assigns DAC especially to the transition economies and the MENA region (Middle East and North Africa). Edmonds et al. sees China, the U.S., and Latin America dominating, when CDR includes both afforestation and BECCS. 


\subsection{Biological and geological constraints on CDR}

All biological strategies in these essays are terrestrial: afforestation and reduced deforestation, biopower without CCS, biopower with CCS (BECCS), and biofuels. They all eventually encounter land constraints. They compete for land with each other and with uses of land for food and fodder, non-food products from forestry and agriculture, recreation, and wilderness preservation.

Limited geological storage capacity for $\mathrm{CO}_{2}$ produces another constraint. The total global $\mathrm{CO}_{2}$ storage capacity, assuming minimal problems with public acceptance, ranges from $2100 \mathrm{GtCO}_{2}$ in Fuss et al. to $7000 \mathrm{GtCO}_{2}$ in Edmonds et al.- in all cases ample for centuryscale conventional fossil-fuel-based CCS, BECCS, and DAC. However, regional storage constraints do arise and give regions with large storage potential a competitive advantage in conducting $\mathrm{CDR}$, provided inter-regional $\mathrm{CO}_{2}$ transport is absent. Inter-regional $\mathrm{CO}_{2}$ trade is subjected to a sensitivity analysis in Chen \& Tavoni.

\subsection{Resulting level of deployment}

Polling the authors of the five IAM papers, after their papers were completed resulted in Tables 1 and 2. Table 1 presents results for CDR as a whole, and Table 2 presents results for BECCS.

Table 1 shows that cumulative CDR for the 21 st century is on the order of $1000 \mathrm{GtCO}_{2}$, bracketed by $500 \mathrm{GtCO}_{2}$ and $1600 \mathrm{GtCO}_{2}$. By comparison, currently, the annual emissions rate from fossil fuels is $30 \mathrm{GtCO}_{2} / \mathrm{yr}$ and the atmosphere contains $3000 \mathrm{GtCO}_{2}$. In Edmonds et al. the ranges for estimated 21 st century CDR from afforestation and BECCS overlap; similarly, Chen \& Tavoni allows both BECCS and DAC and finds comparable contributions. Cumulative CDR activity represents a substantial fraction of total estimated mitigation over the century, roughly 3500 to $4000 \mathrm{GtCO}_{2 \mathrm{e}}$ for stringent climate targets. A CDR contribution of $1000 \mathrm{GtCO}_{2}$ reduces the equilibrium average surface temperature about $0.5^{\circ} \mathrm{C}$, according to the carbon budget approach (Matthews et al. 2012).

The peak rate of CDR activity is similar across all five models, ranging from 10 to 35 $\mathrm{GtCO}_{2} / \mathrm{yr}$. In Edmonds et al., but not in the other four IAM papers, CDR enters significantly early in the century. It enters in the form of afforestation, which quickly becomes competitive with other mitigation options, because terrestrial carbon emissions are penalized and rewarded at the same carbon price as fossil-fuel carbon emissions. The result is early, large, and widespread changes in land-use practices.

In summary, the IAM models show that when strong targets for carbon mitigation are pursued, CDR technologies costing between $\$ 100 / \mathrm{tCO}_{2}$ and $\$ 1000 / \mathrm{tCO}_{2}$ contribute substantially to climate-change mitigation in the second half of the century. Some high-cost mitigation options are never deployed. In the final period of the 21 st century, for the reference case in Fuss et al., one-third of baseline emissions remain unmitigated. In effect, residual emissions enter the atmosphere at one location, and at other locations a net-cumulative-emissions target is met by CDR that removes nearly an equivalent amount of $\mathrm{CO}_{2}$.

Overshoots are reported for three of the five models. They are much smaller in Kriegler et al. and Chen \& Tavoni (40 ppm and $60 \mathrm{ppm}$ for concentration overshoot, $0.05{ }^{\circ} \mathrm{C}$ and $0.06{ }^{\circ} \mathrm{C}$ for temperature overshoot, respectively) than in Edmonds et al. (where the overshoot ranges are $55 \mathrm{ppm}$ to $135 \mathrm{ppm}$ and $0.2^{\circ} \mathrm{C}$ to $0.5^{\circ} \mathrm{C}$ ). The disparities in the ratio of temperature overshoot to concentration overshoot across these three papers reflect differences in the timing of CDR implementation and the lagged relationship between concentration and temperature.

As seen in Table 2, in 2100 the bioenergy contribution to global primary energy ranges from 100 to $300 \mathrm{EJ} / \mathrm{yr}$, across the five papers. By comparison the models estimate roughly 
Table 2 Some $\mathrm{CO}_{2}$ removal parameters in this issue's five integrated assessment models. Data were obtained by polling the authors, and some data are not found in their articles

\begin{tabular}{|c|c|c|c|c|}
\hline Paper & Model and institution & $\begin{array}{l}\text { Price of biomass } \\
\text { in } 2100(\$ / G J)\end{array}$ & $\begin{array}{l}\text { Bioenergy }^{\mathrm{a}} \\
\text { in } 2100 \\
(\mathrm{EJ} / \mathrm{yr})\end{array}$ & $\begin{array}{l}\text { Land for bio-CDR } \\
\text { in } 2100 \text { (Mha) }\end{array}$ \\
\hline Edmonds et al. & GCAM (PNNL) & $\begin{array}{l}3^{c} \\
47 \\
64\end{array}$ & $\begin{array}{l}117 \\
277 \\
300\end{array}$ & $490-530^{\mathrm{d}}$ \\
\hline Van Vuuren et.al. & IMAGE (PBL) & 10 & 250 & $300-600$ \\
\hline Kriegler et al. & REMIND (PIK) & $\begin{array}{l}8^{\mathrm{e}} \\
94^{\mathrm{f}} \\
31\end{array}$ & $\begin{array}{l}183 \\
200 \\
176\end{array}$ & n.a. ${ }^{g}$ \\
\hline Chen and Tavoni & WITCH (FEEM and CMCC) & $\begin{array}{l}4^{\mathrm{h}} \\
40\end{array}$ & 150 & n.a. \\
\hline Fuss et al. & Stylized model (IIASA) & n.a. & 225 & n.a. \\
\hline
\end{tabular}

\footnotetext{
a "bioenergy" 2 is BECCS+biopower without CCS+biofuels

b "bio-CDR" is BECCS + afforestation

${ }^{c}$ The three prices and quantities for Edmonds et al. are for, respectively, the Reference Scenario, the Ideal Scenario, and the Delayed Participation Scenario

${ }^{\mathrm{d}}$ This range is for the Ideal Scenario and Delayed Participation Scenario

e The three prices and quantities for Kriegler et al. are for, respectively, the Baseline Scenario, the \$30Tax Scenario, and the \$30TaxNoBECCS Scenario. The marginal cost of biomass is $\$ 4 / G J$ for all cases, and the difference is due to scarcity rents resulting introducing an upper limit on total biomass at $200 \mathrm{EJ}$

${ }^{\mathrm{f}}$ This is the only price in this column that does not equals the marginal cost. It is higher because a hard supply constraint (200 EJ/yr) takes effect

${ }^{g}$ Not available

${ }^{\mathrm{h}}$ The two prices for Chen and Tavoni are for, respectively, the Baseline scenario and the $490 \mathrm{ppm}$ climate stabilization scenario. Average production costs of biomass are lower than prices, e.g. \$11/GJ for the climate stabilization case
}

$1000 \mathrm{EJ} / \mathrm{yr}$ of total global primary energy at that time. Not all of the bioenergy will appear as BECCS, since some will be for biofuels and some will be for biopower without CCS. Table 2 also reports land requirements of several hundred million hectares (Mha) for biological CDR for the two IAM models that include land explicitly: Edmonds et al. reports 490 Mha and 530 Mha for two scenarios where land is assigned to both afforestation and BECCS, while van Vuuren et al. estimates from 300 Mha to 600 Mha, all for BECCS.

BECCS is first implemented early in the century (around 2030), but most CDR via BECCS is achieved after 2050, when deep cuts in emissions are needed and carbon prices exceed $\$ 100 / \mathrm{tCO}_{2}$. However, BECCS is adversely affected by the rising cost of biomass that reflects its constrained supply. As seen in Table 2, biomass prices in 2100 for three baseline cases without BECCS are between $\$ 3 / \mathrm{GJ}$ and $8 \$ / \mathrm{GJ}$, similar to the models' prices today. But when BECCS is available for the same targets, it produces dramatic upward pressure on the biomass price, which increases to 31-94 \$/GJ, depending on marginal production costs and scarcity rents.

\subsection{Implications for reduced effort on conventional mitigation}

In all five IAM models, CDR availability reduces conventional mitigation early in the century, relative to base cases where no CDR is available. This is expected: in any cost 
optimization over several time periods, knowing for sure that an extra option will be available at a future time reduces the effort expended on every other option at earlier times-relative to the effort to meet the same goal when there is no extra option. The extent of late CDR and associated reduction in early conventional effort depends on the discount rate. The discount rate captures the willingness to transfer mitigation costs to future generations that will also face higher climate damages. Lowering the discount rate indeed reduces the scope for CDR in Chen \& Tavoni. Given the potency for policy making of the issue of appropriate current effort, the sensitivity of specific results to key assumptions in the IAM papers should make the reader cautious about carrying modeling results into the real world.

\section{CDR science and technology}

Mazzotti et al. (2013), Vichi et al. (2013), and Smith and Torn (2013), our three papers dealing with CDR science and technology, all raise issues that complement the integrated assessment models. Mazzotti et al. addresses the "net carbon" aspects of direct air capture (DAC) - DAC's carbon intensity — by exploring a benchmark $\mathrm{CO}_{2}$-absorbing system where $\mathrm{CO}_{2}$ emissions associated with accomplishing DAC can be a significant fraction of $\mathrm{CO}_{2}$ removed from the atmosphere; Chen \& Tavoni treats this generalizable feature of CDR explicitly.

Vichi et al. raises and quantifies the important issue of ocean outgassing associated with $\mathrm{CO}_{2}$ removal from the atmosphere (Kheshgi et al. 2005). Just as $\mathrm{CO}_{2}$ emissions into the atmosphere result in $\mathrm{CO}_{2}$ passing from the atmosphere to the ocean to sustain equilibrium at the ocean's surface, so too do flows from ocean to atmosphere accompany atmospheric removal. Chen \& Tavoni incorporates the results of Vichi et al.

Smith \& Torn presents a systematic quantitative discussion of inputs to biological CDR strategies: land, nitrogen, phosphorus, and water. The authors also quantify the $\mathrm{CO}_{2}$ and nitrous oxide $\left(\mathrm{N}_{2} \mathrm{O}\right)$ emissions associated with these inputs; emissions of $\mathrm{N}_{2} \mathrm{O}$, a potent greenhouse gas, are sensitive to nitrogen inputs and have received little attention. The falling water table usually associated with afforestation is also discussed, as well as soil salination and biodiversity. This paper adds an important dimension to CDR research and raises the prospect that biological versions of CDR may largely transfer environmental risk from the atmosphere to the land.

In the rest of this section, we identify further features of these three papers.

\subsection{Direct air capture with chemicals (Mazzotti et al.)}

Mazzotti et al. presents an optimization of the same benchmark system that was studied, but not optimized, in the report on DAC released in 2011 by the American Physical Society (Socolow et al. 2011). Optimization across three variables (fraction of $\mathrm{CO}_{2}$ captured, air flow velocity, and sorbent solution velocity) reduces the estimated capture cost only slightly, because key cost assumptions for capital equipment are not changed. The cost estimate (in the range of $\$ 500$ per ton of $\mathrm{CO}_{2}$ ) is used as an input in the integrated assessment papers by Fuss et al. and Chen \& Tavoni.

The APS report and Mazzotti et al. propose that $\mathrm{CO}_{2}$ removal from the atmosphere will almost certainly be substantially more expensive than reducing (by retrofit or rebuild) nearly all of the emissions from large and concentrated sources of $\mathrm{CO}_{2}$ at coal and natural gas power plants, refineries, cement plants, and many other industrial facilities. The fundamental 
reason is that the concentration of $\mathrm{CO}_{2}$ in the flue gas at these facilities is much higher than in air. The ratio for a coal power plant is roughly 300-12\% $\mathrm{CO}_{2}$ in the flue gas, $0.04 \%$ in air. This ratio affects the frontal area facing the incoming gas, but this is only one of several contributors to the cost ratio. The path of flue gas at a coal plant can be longer, the percent of $\mathrm{CO}_{2}$ removed can be larger, materials can be allowed to be more expensive, and operating costs can be a higher fraction of total costs. In Mazzotti et al., the ratio of total costs is 6 to 8 .

Several start-up companies are seeking to reduce the cost ratio further. Lackner, for example, speculates that DAC could take the form of large numbers of low-unit-cost factory-produced absorbers. (Lackner et al. 2012) Arguably, DAC could experience greater cost reductions than flue-gas capture, because a DAC facility has only a single objective, whereas conventional CCS at a large industrial facility is an add-on, complicating and compromising the core activity (e.g., producing power). Nonetheless, it is hard to imagine a future where many coal power plants spew their $\mathrm{CO}_{2}$ into the atmosphere while, simultaneously, many DAC plants are removing $\mathrm{CO}_{2}$ from the atmosphere. It seems far more likely that DAC deployment will not begin in earnest until very few large concentrated sources remain.

Perhaps DAC can expand greatly with little change in unit cost, making DAC a "backstop" technology. By contrast, BECCS will eventually reflect land constraints. Moreover, DAC may require much less land per ton of CDR than BECCS and may create fewer land-use conflicts. In common, BECCS and DAC require low-cost, publicly acceptable, and abundant geological storage capacity for $\mathrm{CO}_{2}$.

\subsection{Ocean outgassing (Vichi et al.)}

$\mathrm{CO}_{2}$ is removed from the atmosphere by natural processes that restore equilibrium. Extra $\mathrm{CO}_{2}$ in the atmosphere leads to some fraction dissolving into seawater at the ocean's surface, and a similar redistribution (though much more complicated) occurs for vegetation. Over the past several decades, on average (but with large year-to-year variation) the net atmospheric removal rate has been about half of the emissions rate from fossil fuel combustion (with roughly equal contributions from ocean and land removal). One can anticipate, therefore, that deliberate removal of $\mathrm{CO}_{2}$ from the atmosphere should be accompanied by ocean outgassing of $\mathrm{CO}_{2}$ and (with less certainty) reduction in the global stock of carbon in biomass. These are negative feedbacks on the CDR enterprise. Vichi et al. may be the first paper to estimate ocean outgassing when the $\mathrm{CO}_{2}$ is removed over an extended period of time. Cao and Caldeira estimated ocean outgassing when $\mathrm{CO}_{2}$ is removed from the atmosphere at a single moment (Cao and Caldeira 2008).

Vichi et al. studies two related extended campaigns that in the absence of outgassing would remove about $490 \mathrm{GtCO}_{2}(130 \mathrm{GtC})$ from the atmosphere over a 30 year period (about $16 \mathrm{GtCO}_{2} / \mathrm{yr}$, about half the current rate of fossil fuel emissions). As discussed in the previous section, $\mathrm{CO}_{2}$ removal rates this large and larger are foreseen by the IAMs. In the first campaign, a global CDR industry follows a prescribed emission-reduction schedule: it removes $16 \mathrm{GtCO}_{2} / \mathrm{yr}$ for 30 years and ignores the outgassing; in response $50 \mathrm{GtCO}_{2}$ outgases from the ocean, a $10 \%$ negative feedback. In the second campaign, a global $\mathrm{CDR}$ industry follows assures that the net $\mathrm{CO}_{2}$ removal is $16 \mathrm{GtCO}_{2} / \mathrm{yr}$ when outgassing is taken into account. This requires removing somewhat more than $16 \mathrm{GtCO}_{2} / \mathrm{yr}$, because the concentration difference between ocean and atmosphere is always larger; the associated outgassing is slightly greater, $66 \mathrm{GtCO}_{2}$. The authors warn that their results are specific to an initial atmospheric concentration of $\mathrm{CO}_{2}$ of $348 \mathrm{ppm}$ (the concentration in 1988) and for a 
specific ocean model. Nonetheless, a crude representation of outgassing in Chen \& Tavoni indicates that this negative feedback can significantly reduce the scope for CDR.

Although the terrestrial sink is much less well understood than the ocean sink, by a combination of measurement and modeling a coarse sketch of the geographical distribution of the terrestrial carbon sink is emerging. Eventually, models will incorporate a CDRefficacy factor that accounts for all sources and sinks. For now, a conservative estimate-aligned with the strength of the negative feedbacks from the ocean and land observed today-would assume that a one-ton reduction in the atmospheric stock of $\mathrm{CO}_{2}$ requires two tons of $\mathrm{CO}_{2}$ to be removed from the atmosphere.

\subsection{Land, nutrients, and water for biological CDR (Smith \& Torn)}

Smith \& Torn studies the environmental aspects of two biological CDR strategies: BECCS and afforestation. Their BECCS system is based on switchgrass grown in a temperate climate. Afforestation is modeled as 50 years of carbon build-up in tropical eucalyptus plantations. In both cases, these choices are intended only to be illustrative: to illuminate qualitative issues common to many biomass strategies and to provide templates for analogous calculations bearing on other species and locations. They estimate demands on land, water, nitrogen, and phosphorus and they identify impacts on albedo, biodiversity, and land tenure. All quantitative estimates are scaled, helpfully, to a global enterprise removing carbon dioxide from the atmosphere at a rate of $3.7 \mathrm{GtCO}_{2} / \mathrm{yr}(1 \mathrm{GtC} / \mathrm{yr})$. Here, we report a few of their sobering results.

The key estimate is the productivity of land, i.e., the yield in tons per hectare-year (t/ha-yr). For the Smith \& Torn switchgrass plantation producing feedstock for BECCS, the estimated yield is 5.6 to $23 t_{\text {biomass }} /$ ha-yr. Note that the high estimate is four times larger than the low estimate. Assuming that the carbon intensity of energy from switchgrass is $15 \mathrm{GJ} / \mathrm{t}_{\text {biomass }}$, the estimated yield of primary energy in the form of switchgrass feedstock (rounding off) is 80 to $350 \mathrm{GJ} / \mathrm{ha}$-yr. Compare this range with the primary biomass energy yield at the end of the century assumed for two scenarios in Edmonds et al., $600 \mathrm{GJ} / \mathrm{ha}-\mathrm{yr}$ (about $300 \mathrm{EJ} / \mathrm{yr}$ grown on about 500 Mha, see Table 2). A rate of improvement of yields of $0.6 \% / y r$ to $2.3 \% / y r$ for 90 years would be required for Smith \& Torn's estimated yield today to grow to the yield in 2100 in Edmonds et al. This range brackets the $1.6 \% / y r$ long-run record of yield improvement reported by the Food and Agriculture Organization of the United Nations.

The "net carbon" issues for DAC explored in Mazzotti et al. reappear in the BECCS system examined by Smith \& Torn. The authors estimate that about 2.2 tons of carbon must be fixed in switchgrass by photosynthesis for each ton of carbon sequestered as $\mathrm{CO}_{2}$ in a geological formation via BECCS, to compensate for emissions associated with harvesting, transport, and electricity production. Smith and Torn report that switchgrass is $42 \%$ carbon; as a result, to sequester one ton of carbon per year via BECCS will require growing 5.2 tons of biomass per year, corresponding to 0.23 to 0.94 hectares.

As for land demands for afforestation at eucalyptus plantations, Smith \& Torn assume that carbon builds up in trees for 50 years at an average rate of 1.3 to $4.0 \mathrm{tC} / \mathrm{ha}-\mathrm{yr}$. Thus, each ton per year of CDR via afforestation will require 0.25 to 0.77 hectares. Evidently, in Smith \& Torn, the land required for an identical level of CDR activity is nearly the same for a fiftyyear afforestation project and for BECCS. At the end of the 50 years, new land will be needed for afforestation (the eucalyptus trees will have reached maximum size), but, in principle, the land planted in switchgrass for BECCS can keep producing.

If hundreds of millions of hectares are dedicated to carbon management, other land will experience knock-on effects. For example, a change from pasture to energy crop for BECCS 
will require that fodder be grown elsewhere and may elicit feedlot cattle-raising. These knock-on consequences are subsumed under the label, "indirect land-use change," or "ILUC" (Searchinger et al. 2008; Fargione et al. 2008). They will have their own climate impacts - not only $\mathrm{CO}_{2}$ emissions but also changes in albedo and evapotranspiration. Including ILUC in the assessments of BECCS and afforestation was beyond the scope of Smith \& Torn.

Smith \& Torn estimates that an average application rate of $80 \mathrm{kgN} / \mathrm{ha}$-yr of nitrogen fertilizer is required to achieve the assumed switchgrass yields. The Smith \& Torn reference CDR level of $1 \mathrm{GtC} / \mathrm{yr}\left(3.7 \mathrm{GtCO}_{2} / \mathrm{yr}\right)$, therefore, will require an annual input of 19 to 75 million tons of nitrogen. By comparison, today's annual global fertilizer production provides about 100 million tons of nitrogen. Today's rate also roughly equals the global rate of biological fixation of atmospheric nitrogen by microorganisms. Increased nitrogen availability has fed the world, but it has also had many adverse environmental consequences, such as eutrophication of coastal waterways and increased production of nitrous oxide $\left(\mathrm{N}_{2} \mathrm{O}\right)$, a potent greenhouse gas. BECCS can be expected to exacerbate these adverse consequences, even as it retards climate change. The authors speculate, however, that future nitrogen requirements to achieve the same yield will decline as fertilizer is delivered more effectively.

Hundreds of millions of hectares dedicated to biomass CDR is an immense demand on land. Integrated assessment models that call for large demands on land have long incorporated ecological constraints that reduce the scope for bio-energy in climate change mitigation (van Vuuren et al. 2009). It is already time for broad discussion of these ecological constraints and their implications. Climate mitigation modelers, land use planners, agricultural economists, agronomists, foresters, plant physiologists, and genetic engineers - this is only a partial list of those who must participate.

\section{The CDR policy research frontier}

James Meadowcroft, in the one article in this special issue written from the perspective of political science (Meadowcroft 2013), identifies three important topics on the CDR policy research frontier that we develop in this section: 1) the "pace" at which CDR could grow, 2) the threats that CDR does and does not address, and 3) CDR in a world conducting iterative decision-making. All three are good candidates for new research.

\subsection{Pace of change}

Every attempt to describe how the future differs from the present must deal with the question of how quickly change can occur — what we call the "pace of change" (or, simply, "pace"). Integrated assessment modeling, for example, embeds constraints that prevent one component of the energy system, such as nuclear power, from displacing all its competitors in a single decade, even if the model introduces a technological breakthrough that suddenly lowers this alternative's cost. Necessarily, judgment is required to quantify constraints on pace. History can help by providing evidence bearing on the time required, for example, for one energy alternative (such as automobiles) to displace another (such as horses). Nothing happens overnight.

Pace for the biological CDR options is constrained by how quickly land use can change. In the reference case (T1) in Edmonds et al., a uniform price on biological and fossil fuel carbon of $\$ 16 / \mathrm{tCO}_{2}(\$ 60 / \mathrm{tC})$ is imposed in 2015-2020, which "dramatically changes the 
economics of land use and dramatically changes the allocation of land in the model." (See Edmonds et al., Supporting Online Material.) As a result, in that same initial time step, no less than one billion hectares of land "change use to forest systems predominantly, but not exclusively, in the tropics." This is the land area of the United States. On average, each hectare undergoing afforestation is sequestering $4 \mathrm{tC} / \mathrm{yr}$ (15 $\mathrm{tCO}_{2}$ ) by 2020 , resulting in a new land sink of $15 \mathrm{GtCO}_{2} / \mathrm{yr}$ that cancels roughly half of the world's fossil fuel emissions. The average "pace" of this rapid increase is 3 $\mathrm{GtCO}_{2} / \mathrm{yr}^{2}$. Bottlenecks that might constrain land use change on one billion hectares in a five-year period that begins just two years from now are not internal to this specific mitigation strategy in this specific model.

To take pace into account and penalize overly rapid deployment, Kriegler et al. introduces "adjustment costs" on the rate of capacity expansion. Van Vuuren et al. observes that the "emission reduction rate" (our "pace") is constrained by the cost of "premature retirement" as well as "the inertia in the change of consumer preferences, international negotiation processes, policy formulation and the maximum deployment rate of new technologies... These factors are very uncertain and typically not captured in energy-economic models." Meadowcroft, contemplating large-scale CDR quite generally, writes: "Scale must also be thought about in terms of the human activity required to realize the approach, the scope of existing societal practices that must be transformed, the land-use footprint and potential environmental impacts. And this suggests ambitious estimates of CDR potentials-especially by mid-century - must be viewed with caution."

All CDR modeling will eventually take pace into account. For DAC, constraints on pace arise from limits on the rate of build-up, globally, of specific industrial activity, such as cement or steel production, and the fraction of such a build-up that could be dedicated to DAC. Historical precedents might be sought in the rates of build-up observed during wartime mobilization or, perhaps, in the rates of increase in specific industrial sectors (such as road and building construction) during the recent period of high economic growth in China.

The CDR pace can be quantified in the units of the "stabilization wedge" (Pacala and Socolow 2004; Socolow and Lam 2007). A wedge is defined by linear growth of a carbon-responsive strategy over 50 years, starting from no activity at all and rising to an activity level of $1 \mathrm{GtC} / \mathrm{yr}$. A one-wedge pace, therefore, is $0.02 \mathrm{GtC} / \mathrm{yr}^{2}$, or 0.073 $\mathrm{GtCO}_{2} / \mathrm{yr}^{2}$. Thus, the pace of afforestation discussed above, $3 \mathrm{GtCO}_{2} / \mathrm{yr}^{2}$, is a 40 wedge pace. Constraints on pace are an important challenge to modeling in general and to the modeling of CDR in particular.

\subsection{Matching CDR to threats}

Yet another frontier of CDR research would scope out CDR's capacity to respond to threats arising from climate change. Threats can be chronic or acute. A chronic threat could take the form of a "new normal" in climate that is widely judged to be unfavorable, relative to an earlier climate. An acute threat would be a "climate emergency": the sudden appearance of a dangerous manifestation of climate change that threatens to overwhelm civilization.

To counter a chronic threat, $\mathrm{CDR}$ may be used someday to lower the atmospheric $\mathrm{CO}_{2}$ concentration. At such a time nearly all fossil fuel emissions would have ended. How quickly could the $\mathrm{CO}_{2}$ concentration be reduced? As summarized in Table 1, the papers in this issue contemplate $\mathrm{CDR}$ at 15 to $30 \mathrm{GtCO}_{2} / \mathrm{yr}$ by 2100 . Conservatively, at this rate of deployment, the $\mathrm{CO}_{2 \mathrm{e}}$ concentration will fall by 1 to $2 \mathrm{ppm} / \mathrm{yr}$ (see above). Think 550 ppm being lowered to 450 ppm over 50 to 100 years. In short, CDR could 
be matched to a globally coordinated deliberative process that adjusts the atmospheric concentration on a century-scale.

CDR, however, is not matched to a climate emergency, which is likely to require that an effective response be mounted over a decade or so. Examples of emergencies are rapid melting of the Greenland icesheet and rapid outgassing of methane now sequestered in buried ice in structures known as clathrates. It is possible, however, that a sufficiently rapid response could be generated by Solar Radiation Management (SRM). The objective of SRM strategies is to increase the percent of incoming sunlight reflected by the planet (e.g., from its current value of $31 \%$ to $32 \%$ ), thereby countering the warming by greenhouse gases. Strategies to increase the planet's reflectivity include making clouds whiter and injecting reflective particles into the stratosphere. Often today CDR and SRM are presented as two versions of "geoengineering"- - a word intended to encompass all forms of deliberate intervention in the earth's physical, chemical, and biological systems at the planetary scale (Royal Society 2009).

\subsection{Iterative decision-making}

The world is certain to surprise us. In order to be responsive to the uncertainties that lie ahead, several IPCC assessments and a recent report from the National Academy of Sciences, America's Climate Choices (National Research Council of the National Academies 2011) recommend "iterative risk management."

Iterative risk management is essential for CDR, where uncertainty permeates every aspect. Consider three sources of uncertainty. First, uncertainty looms over the stabilization target, and, as seen in several of the papers in this issue, the extent of deployment of CDR is tightly coupled to the climate objective. In the modeling analysis in this special issue, the target-setting process is idealized as the setting of a global target very soon and its retention without modification throughout the century. This idealization is mathematically convenient, but it obviously does not capture reality. Modeling should be able to explore the robustness of early actions in a world where countries continually revise their climate change policies and targets and, through some collective process, iterate global targets (Haurie et al. 2011). Revisions in national policies and practices will reflect both the evolution of climate science and what nations learn from experience about the effectiveness of their own and other countries' mitigation and adaptation efforts.

The competitiveness of fossil fuels is a second major source of uncertainty. Oversimplifying, there are two views today about how quickly the fossil-fuel era can be brought to a close: in just a few decades or in more like a full century. Underlying this difference in views are judgments not only about the urgency of dealing with climate change but also judgment about the competitiveness of fossil fuels (without CCS), relative to lowcarbon alternatives (Socolow 2012).

A third uncertainty surrounds judgments about what Meadowcroft calls the "social impacts" of technology. Meadowcroft writes: "Typically it is only as a technology is rolled out into society that one can get a firm grip on the timing and strength of side effects, the operation of countervailing forces, and the mobilization of direct opposition." For example, biological versions of CDR will undergo periodic assessment of impacts on land tenure and property rights that could affect level of deployment.

Uncertainties about targets, fossil-fuel competitiveness, and social impacts of CDR are obviously linked. Analysis on behalf of iterative decision-making regarding the value of CDR will require contributions from practitioners of disciplines only minimally represented in the articles in this issue, including policy analysts, political scientists, lawyers, economists, psychologists, and sociologists. 


\section{Messages}

We summarize with five messages:

- In pursuit of stringent $\mathrm{CO}_{2 \mathrm{e}}$ emissions reduction, particularly at late stages when much emissions reduction has already been accomplished, carbon dioxide removal (CDR) strategies could become competitive with further deployment of conventional mitigation strategies. In particular, $\mathrm{CO}_{2}$ removal could conceivably substitute for the elimination of the most recalcitrant emissions, such as those from aircraft.

- To play a dominant role, however, CDR technologies would be needed in daunting quantities. It is far from certain that positive net environmental and societal benefits from CDR at very large scale will be achievable. For biological versions of CDRs, a full assessment will require continued improvements in understanding of the coupling of land and atmospheric impacts of bioenergy technologies. For versions of CDR requiring large amounts of $\mathrm{CO}_{2}$ sequestration, much further development of $\mathrm{CO}_{2}$ infrastructure and experience with $\mathrm{CO}_{2}$ storage will be required.

- When models explore a steadfast commitment early in this century to the achievement of a stringent $\mathrm{CO}_{2 \mathrm{e}}$ concentration target late in the century, $\mathrm{CDR}$ technologies are introduced mostly late in the century. The burden of emission reductions shifts forward slightly, in favor of actions late in the century when better technology and greater global affluence are expected. As a result, the costs of mitigation are rebalanced across generations and across countries and regions. During the first half of the century, in all cases, a commitment to stringent targets requires a vigorous decarbonization of the global economy, especially in the power sector, and largely without CDR.

- CDR could be instrumental in actually reducing the atmospheric $\mathrm{CO}_{2 \mathrm{e}}$ concentration and the associated globally averaged surface temperature, once fossil-fuel-based $\mathrm{CO}_{2}$ emissions have been largely eliminated. However, $\mathrm{CDR}$ on its own can reduce the atmospheric $\mathrm{CO}_{2}$ concentrations only very slowly: think, $1 \mathrm{ppm} / \mathrm{yr}$. A CDR campaign actually to reverse climate damage, if it could be done at all, would probably extend over a century or more.

- The modeling of CDR in integrated assessments can be enriched by further iterative dialog with other disciplines. It is not too early to foster communication among those who model optimized century-scale responses to climate change, those who are scoping the opportunities and challenges associated with CDR technologies, and those who are thinking about policy instruments.

Open Access This article is distributed under the terms of the Creative Commons Attribution License which permits any use, distribution, and reproduction in any medium, provided the original author(s) and the source are credited.

\section{References}

Cao L, Caldeira K (2008) Atmospheric stabilization and ocean acidification. Geophys Res Lett 35:L 19609 Chen C, M Tavoni (2013) Direct air capture of $\mathrm{CO}_{2}$ and climate stabilization: a model based assessment. Clim Chang. doi:10.1007/s10584-013-0714-7

den Elzen M, van Vuuren D (2007) Peaking profiles for achieving long-term temperature targets with more likelihood at lower costs. Proc Natl Acad Sci 104-96-17931-17936

Edmonds J, P Luckow, K Calvin, M Wise, J Dooley, P Kyle, L Clarke (2012) Can radiative forcing be limited to $2.6 \mathrm{~W} / \mathrm{m}^{2}$ without negative emissions from bioenergy $\mathrm{AND} \mathrm{CO}_{2}$ capture and storage? Clim Chang. doi:10.1007/s10584-012-0678-z 
Fargione J, Hill J, Tilman D, Polasky S, Hawthorne P (2008) Land clearing and the biofuel carbon debt. Science 319(5867):1235-1238

Fuss S, Reuter WH, Szolgayova J, Obersteiner M (2013) Negative emission technology and the impact of carbon sink uncertainty on mitigation strategies. Clim Chang. doi:10.1007/s10584-012-0676-1

Haurie A, Tavoni M, van der Zwaan B (2011) Modeling uncertainty and the economics of climate change: recommendations for robust energy policy. Environ Model Assess. doi:10.1007/s10666-011-9271-5

Kheshgi H, Smith SJ, Edmonds J (2005) Emissions and atmospheric $\mathrm{CO}_{2}$ stabilization: long-term limits and paths. Mitig Adapt Strateg Glob Chang Clim Chang Environ Policy 10:213-220

Kriegler E, Edenhofer O, Reuster L, Luderer G, Klein D (2013) Is atmospheric carbon dioxide removal a game changer for climate change mitigation? Clim Chang. doi:10.1007/s10584-012-0681-4

Lackner SK, Brennan S, Matter JM, Park AHA, Wright A, Van der Zwaan B (2012) The urgency of the development of $\mathrm{CO}_{2}$ capture from ambient air. Proc Natl Acad Sci 109(33):13156-13162

Matthews HD, Solomon S, Pierrehumbert R (2012) Cumulative carbon as a policy framework for achieving climate stabilization. Phil Trans R Soc A 370:4365-4379

Mazzotti M, Baciocchi R, Desmond MJ, Socolow RH (2013) Direct air capture of $\mathrm{CO}_{2}$ with chemicals: optimization of a two-loop hydroxide carbonate system using a countercurrent air-liquid contactor. Clim Chang. doi:10.1007/s10584-012-0679-y

Meadowcroft J (2013) Exploring negative territory: carbon dioxide removal and climate policy initiatives. Clim Chang. doi:10.1007/s10584-012-0684-1

National Research Council of the National Academies (2011) America's climate choices. National Academies Press. Available at http://www.nap.edu/catalog.php?record_id=12781

Pacala S, Socolow R (2004) Stabilization wedges: solving the climate problem for the next 50 years with current technologies. Science 305(5686):968-972

Royal Society (2009) Geoengineering the climate: science, governance, and uncertainty. Royal Society Publishing

Searchinger T, Heimlich R, Houghton RA, Dong F, Elobeid A, Fabiosa J, Tokgoz S, Hayes D, Yu T (2008) Use of US croplands for biofuels increases greenhouse gases through emissions from land-use change. Science 319(5867):1238-1240

Smith LJ, Torn MS (2013) Ecological limits to terrestrial biological carbon dioxide removal. Clim Chang. doi:10.1007/s10584-012-0682-3

Socolow R (2012) Truths we must tell ourselves to manage climate change. Vanderbilt Law Rev 65(6):1455-1478

Socolow R, Lam H (2007) Good enough tools for global warming policy making. Philos Trans R Soc Ser A Math Phys Eng Sci 365(897-934):2007

Socolow R et al. (2011) Direct air capture of $\mathrm{CO}_{2}$ with chemicals: a technology assessment for the American Physical Society Panel on Public Affairs. Available at: http:/www.aps.org/policy/reports/popareports/ loader.cfm?csModule $=$ security $/$ getfile $\&$ PageID $=244407$

Tavoni M, Tol R (2010) Counting only the hits: the risk of underestimating the costs of stringent climate policies van Vuuren D, van Vliet J, Stehfest E (2009) Future bio-energy potential under various natural constraints. Energy Policy 37(11):4220-4230

van Vuuren D, Deetman S, van Vliet J, van den Berg M, van Ruijven B, Koelbl B (2013) The role of negative $\mathrm{CO}_{2}$ emissions for reaching $2{ }^{\circ} \mathrm{C}$-insights from integrated assessment modeling. Clim Chang. doi:10.1007/s10584-012-0680-5

Vichi M, Navarra A, Fogli PG (2013) Adjustment of the natural ocean carbon cycle to negative emission rates. Clim Chang. doi:10.1007/s10584-012-0677-0 